\title{
EVALUATION OF CRASH TESTS OF THE INSTITUTE OF FORENSIC ENGINEERING, UNIVERSITY OF ZILINA, AIMED AT EES
}

For the proper analysis of traffic accidents it is important to properly evaluate the deformation work of a vehicle deformation based on the extent of damage of the vehicle. The Institute of Forensic Engineering, University of Zilina, made a series of vehicles crash tests focused on the evaluation of the vehicle deformation work. The article focuses the on evaluation of the vehicle deformation work or of the EES (energy equivalent speed) and comparison of stiffness tests of cars (production year around 2000) and older generation of vehicles (which were subject of tests - Crash tests DSD LINZ 1996).

Keywords: Crash test, deformation work, EES (energy equivalent speed), deceleration, deformation depth, stiffness.

\section{Preface}

The Institute of Forensic Engineering, University of Zilina, made in the course of 2012 a series of 5 vehicles crash tests focused on the evaluation of the vehicle deformation work, or of the EES of a vehicle, upon its impact with a fixed, non-deformable barrier with a full overlap.

\section{Conditions of crash tests}

\subsection{Crash vehicles}

For crash tests we used 5 vehicles with the age structure shown in Table 1. By yellow colour is highlighted a period when a given type of vehicle was produced, and by a red dot is marked the production year of the vehicle used in the crash test.
Photo documentation of individual vehicles before relevant crash test, including Euro NCAP evaluation of a given vehicle, is shown in Fig. 1.

\subsection{Crash barrier}

In the crash tests the vehicles were accelerated to the impact velocity by the Mercedes trailer and a pulley system, and they crashed into a solid concrete barrier of weight $10,000 \mathrm{~kg}$ (see Fig. 2).

But the given weight of the barrier was not sufficient to ensure a condition that no significant displacement of the barrier occurs, and therefore, the barrier was fixed using a blade of a recovery tank of weight $35,000 \mathrm{~kg}$ (see Fig. 3).

\begin{tabular}{|l|l|l|l|l|l|l|l|l|l|l|l|l|l|}
\hline & 1993 & 1994 & 1995 & 1996 & 1997 & 1998 & 1999 & 2000 & 2001 & 2002 & 2003 & 2004 & 2005 \\
\hline Nissan Primera & & & & & & & 0 & & & & & & \\
\hline Renault Laguna & & & & & & & 0 & & & & & & \\
\hline Renault Scenic & & & & & & & 0 & & & & & & \\
\hline Audi A6 & & & & & & & & 0 & & & & & \\
\hline Honda Accord & & & & & & & & & 0 & & & & \\
\hline
\end{tabular}

\footnotetext{
* Pavol Kohut, Gustav Kasanicky

Institute of Forensic Engineering, University of Zilina, Slovakia, E-mail: pavol.kohut@usi.sk
} 

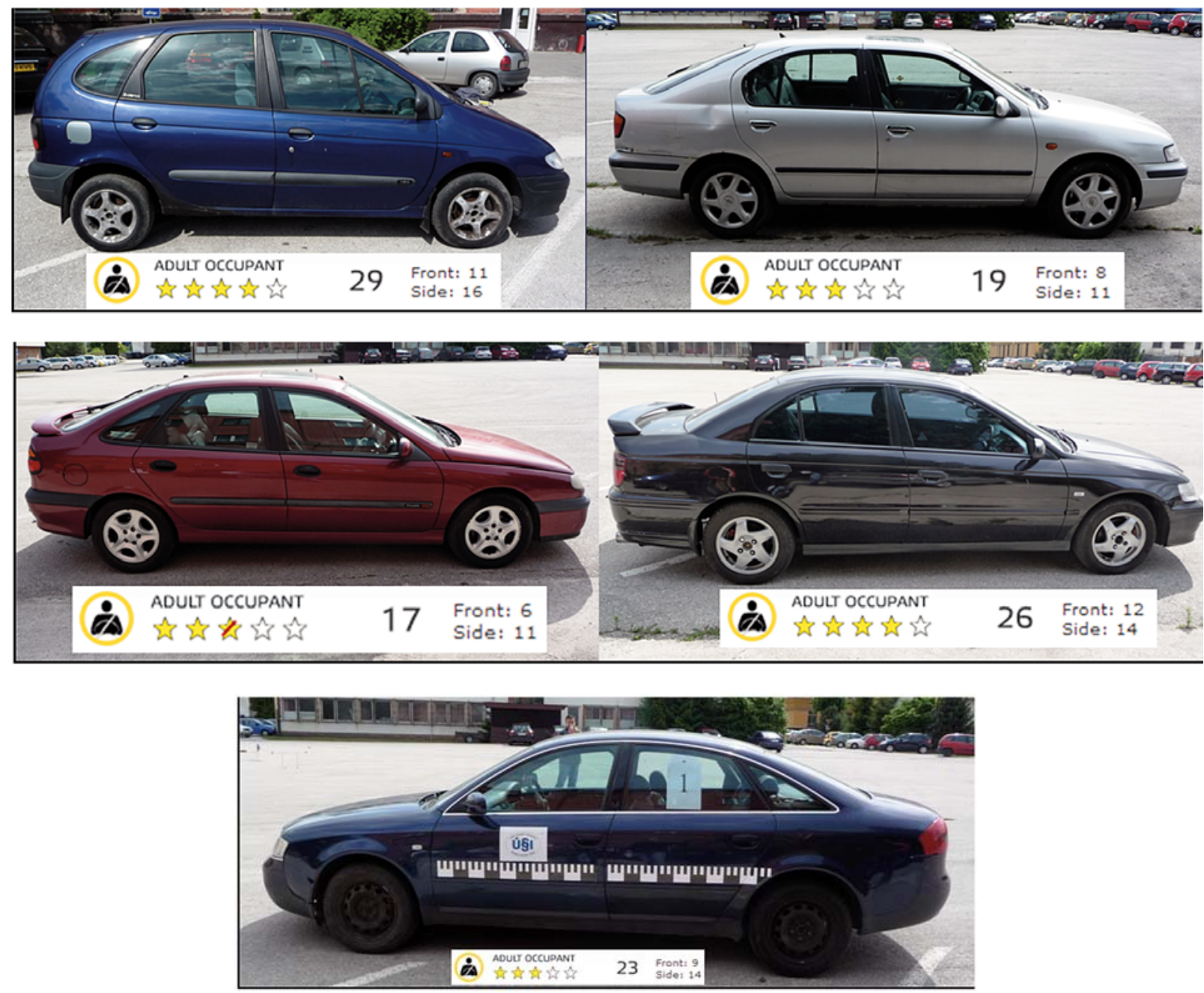

Fig. 1 Photo documentation of passenger cars (before crash test)

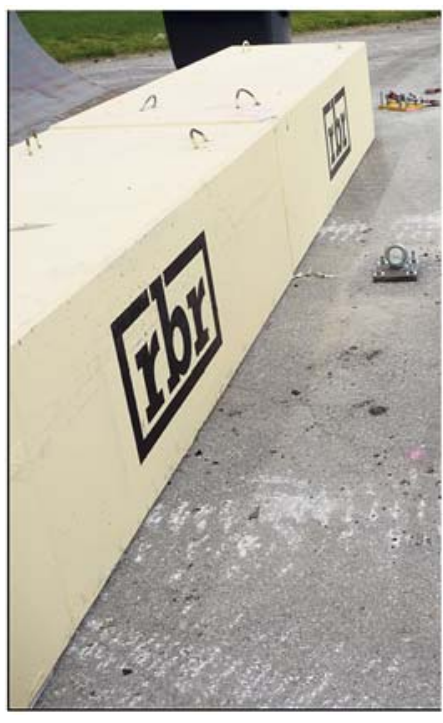

Fig. 2 Concrete solid barrier

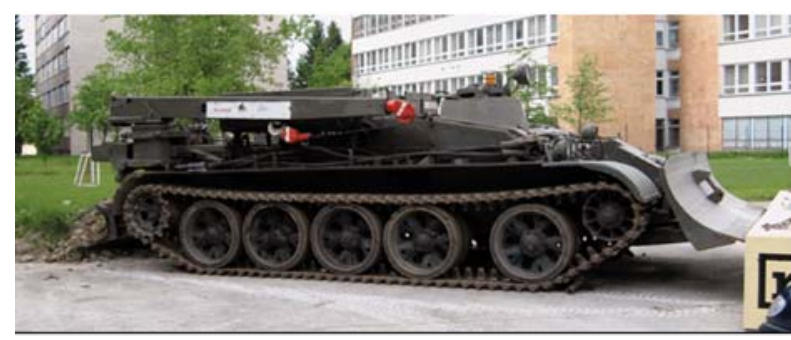

Fig. 3 Recovery tank

3. The results of crash tests

The following photos show (Figs. 4, 5, 6, 7 and 8) the damage to the vehicles after given crash tests, while in the description of the photo is always included the EES value, corresponding to the given damage. 
COMMNICOIIONS

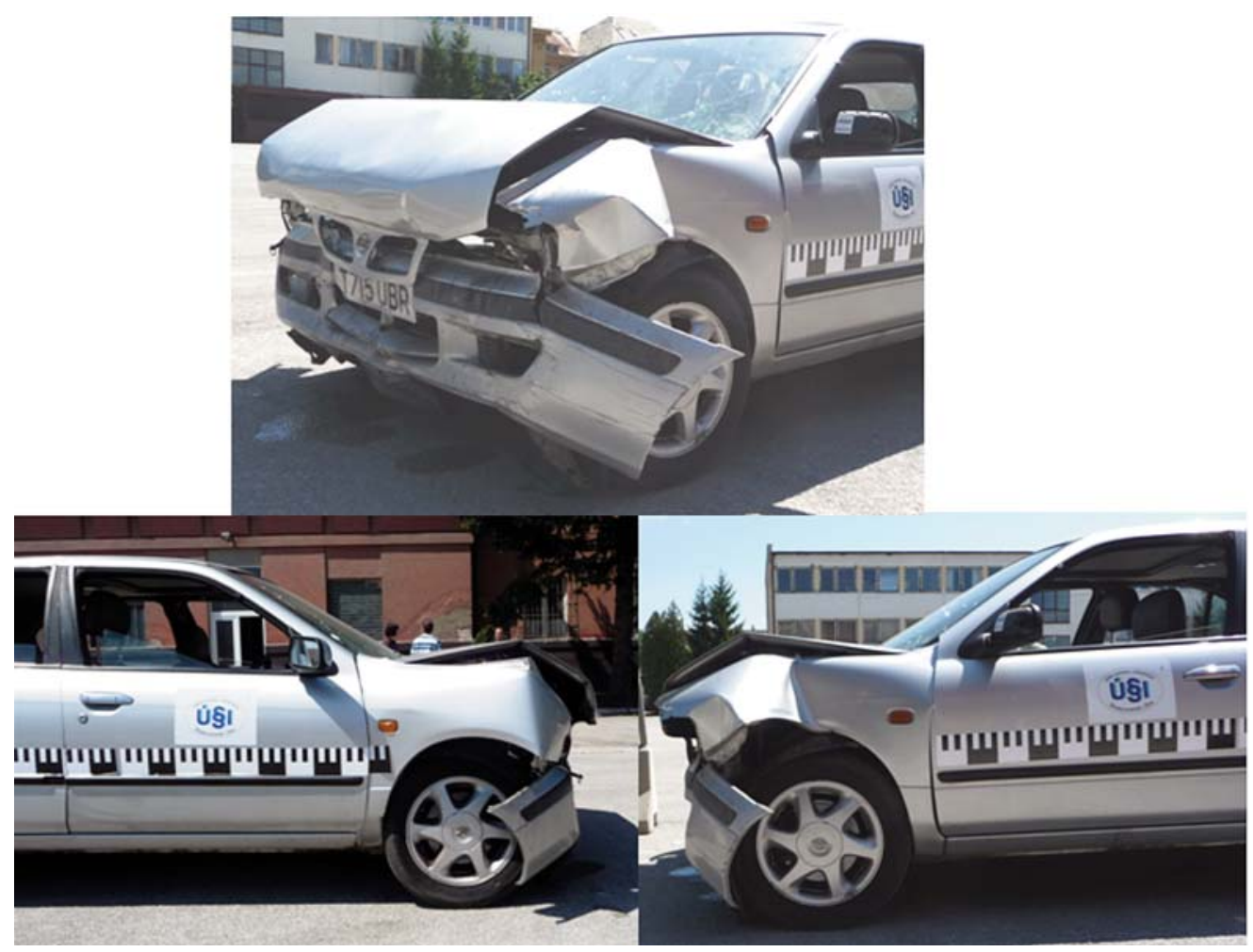

Fig. 4 Damage of the car Nissan Primera $(E E S=54 \mathrm{~km} / \mathrm{h})$

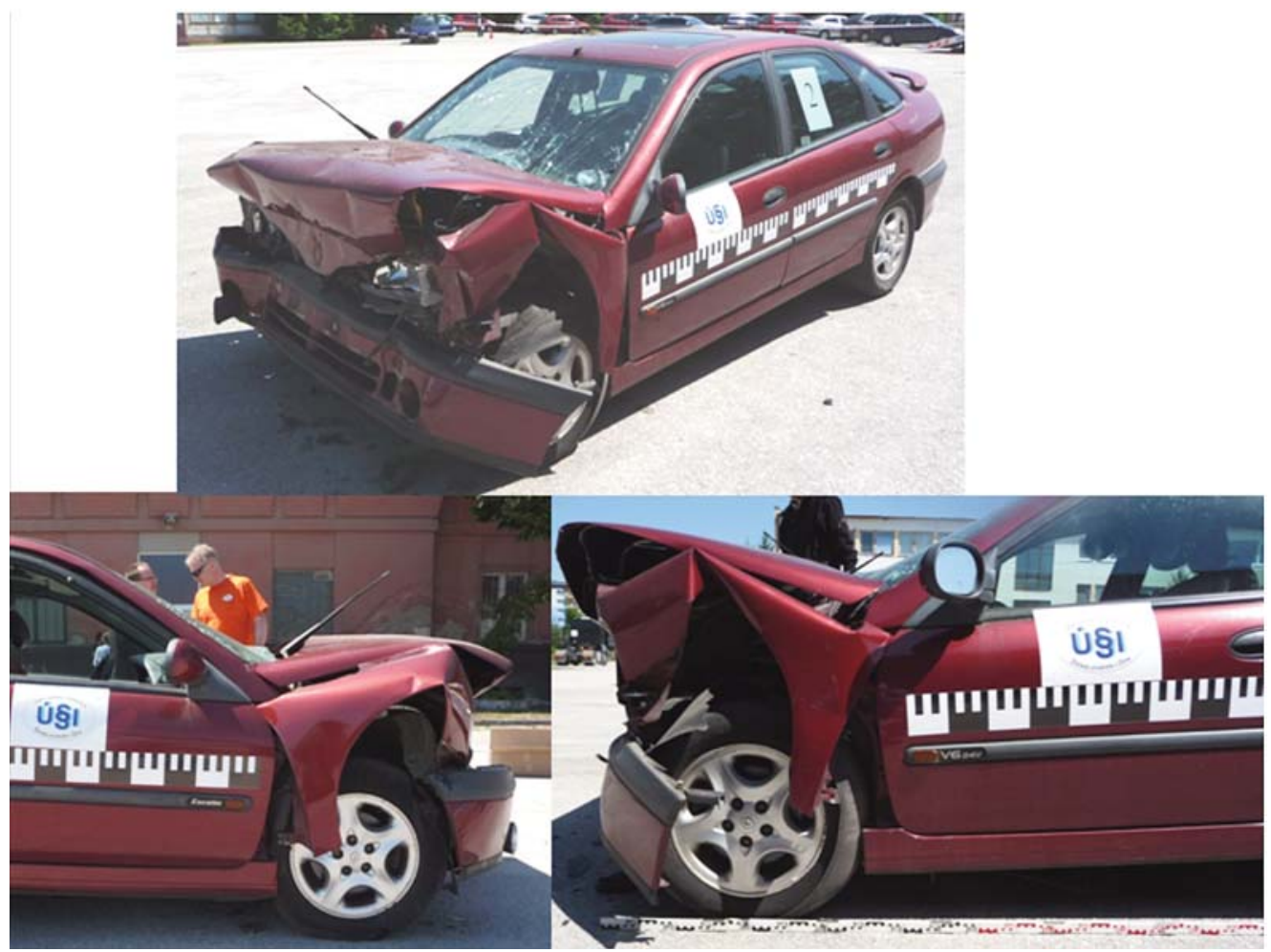

Fig. 5 Damage of the car Renault Laguna $(E E S=62 \mathrm{~km} / \mathrm{h})$ 


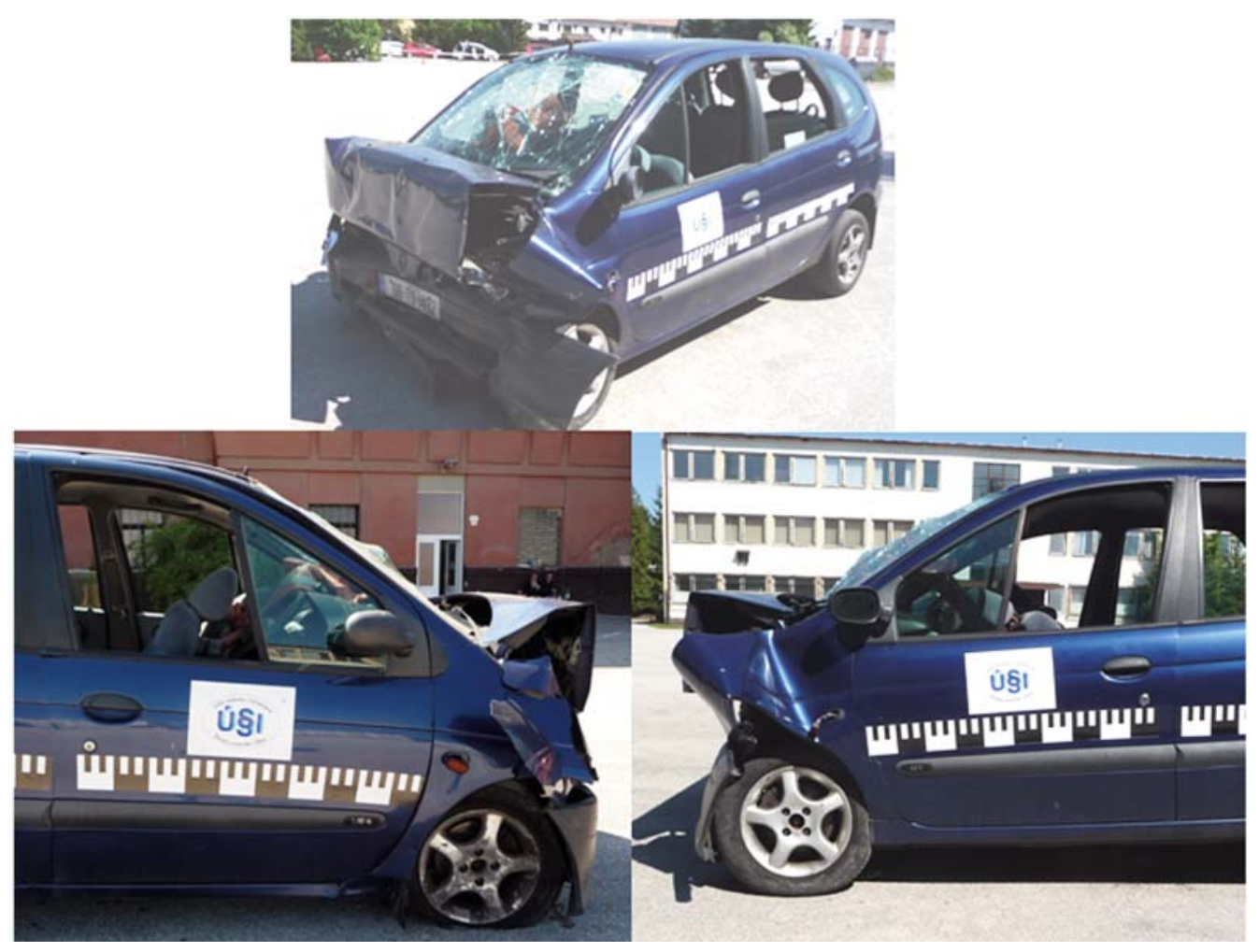

Fig. 6 Damage of the car Renault Megane Scenic $(E E S=72 \mathrm{~km} / \mathrm{h})$

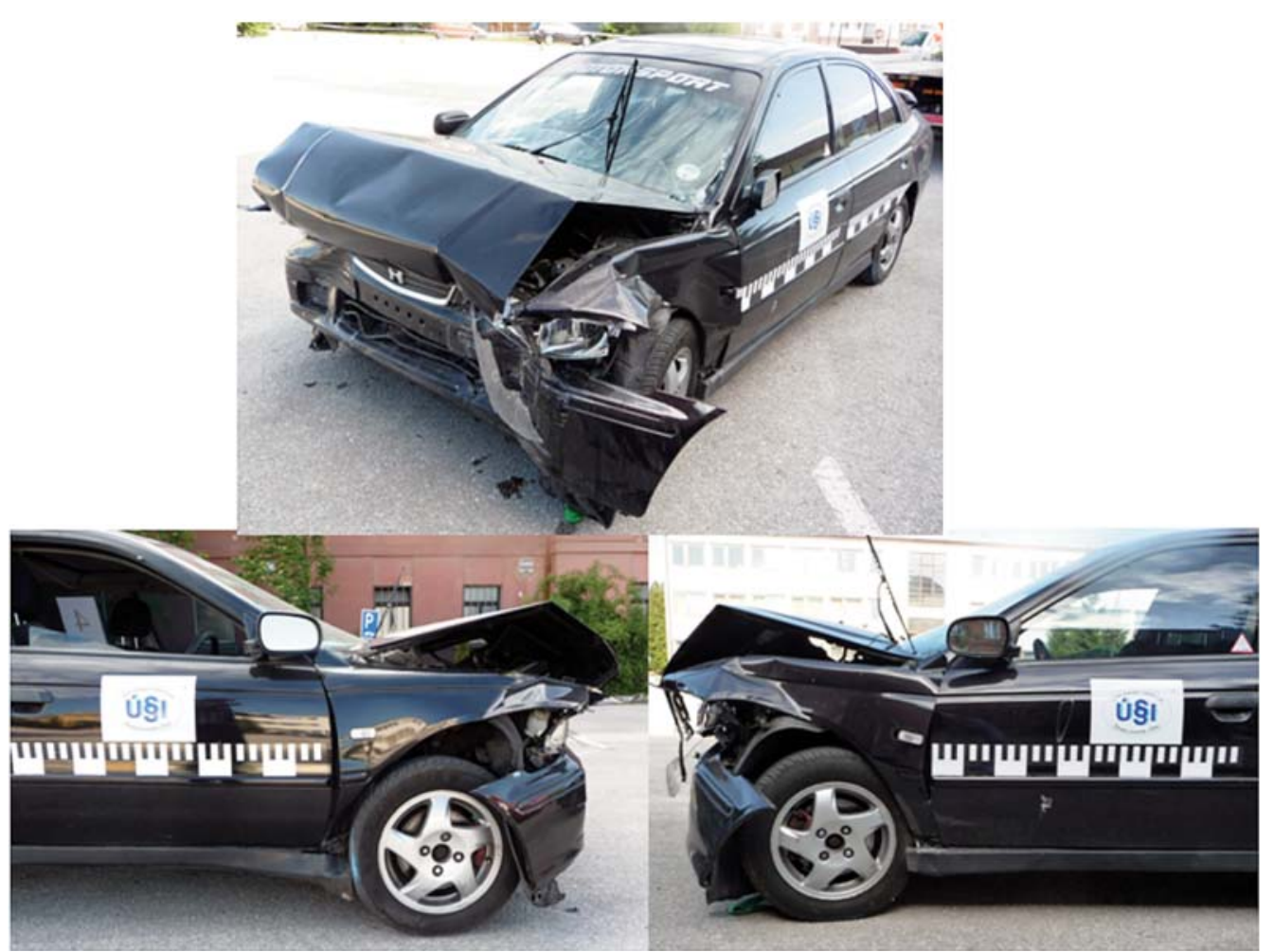

Fig. 7 Damage of the car Honda Accord $(E E S=58 \mathrm{~km} / \mathrm{h})$ 


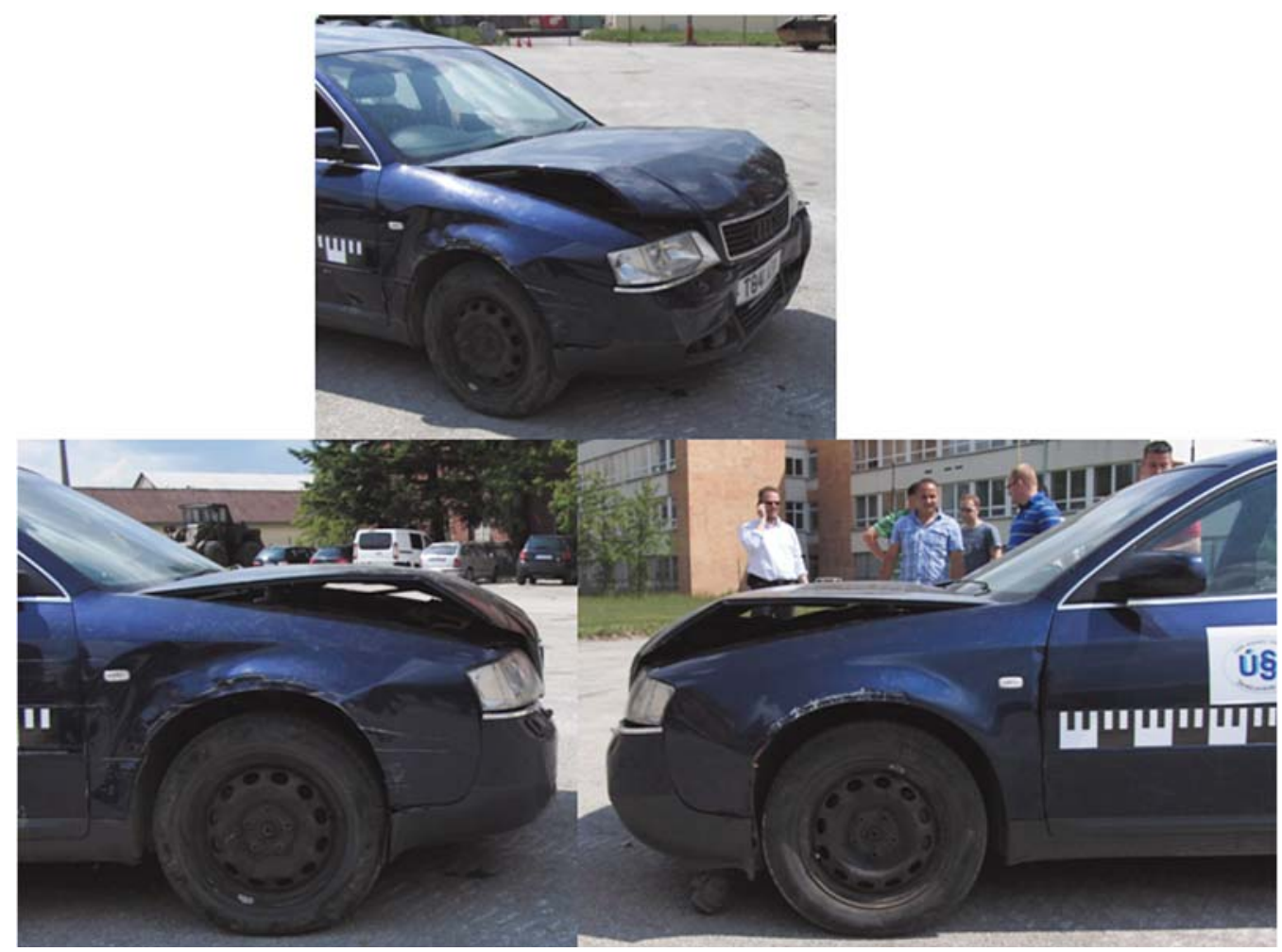

Fig. 8 Damage of the car Audi $(E E S=18 \mathrm{~km} / \mathrm{h})$

The course of a vehicle deceleration was captured by the crash meter, while the time-depending course of Renault Laguna vehicle deceleration is shown in Fig. 9.

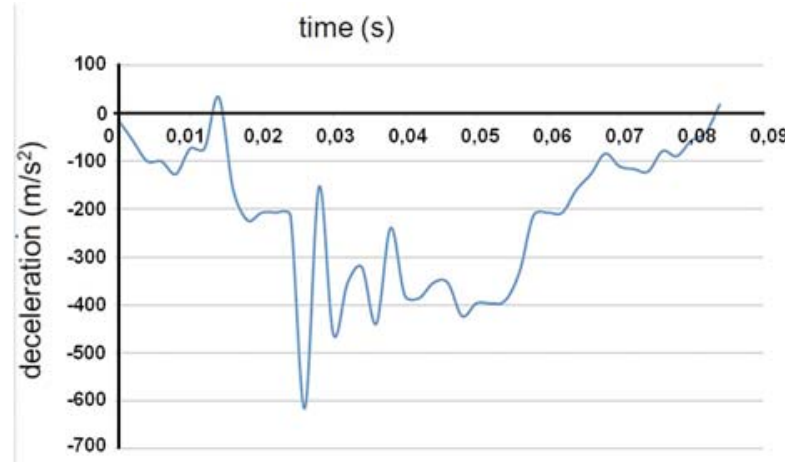

Fig. 9 Time - deceleration diagram

In Fig. 9 above is recognizable considerable oscillation caused by the natural frequency of the measuring device, by a fixing method of the measuring device, as well as by the oscillation of the measuring point (trunk floor of the vehicle) during the impact. For further evaluation it was therefore necessary to filter out the resulting oscillation, and thus the time-depending course of decel- eration of the given vehicle was obtained (for each vehicle). In Fig. 10 the filtered course for Renault Laguna vehicle is shown.

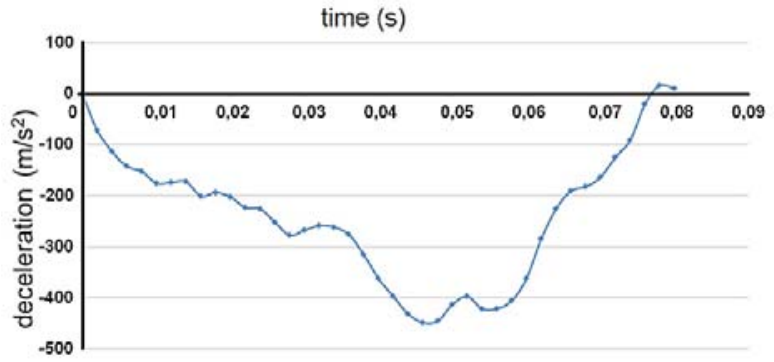

Fig. 10 Time - deceleration diagram (Renault Laguna)

The time-depending course of deceleration was integrated according to the following formula:

$$
v=\int_{t_{0}}^{t_{1}} a(t) d t
$$

where: $a(t)$ - time-depending course of deceleration.

By the mentioned integration the time-depending course of the velocity was obtained. This course was consequently integrated by the following formula: 


$$
s=\int_{t_{0}}^{t_{1}} v(t) d t
$$

where: $v(t)$ - time-depending course of the velocity.

Consequently, from the obtained data of the path and deceleration a path-deceleration diagram was constructed (during the tests). In Figs. 11, 12 and 13 the individual diagrams for the tested vehicles are shown. For Renault Megane Scenic vehicle, the crash meter broke down and the correct record was not captured.

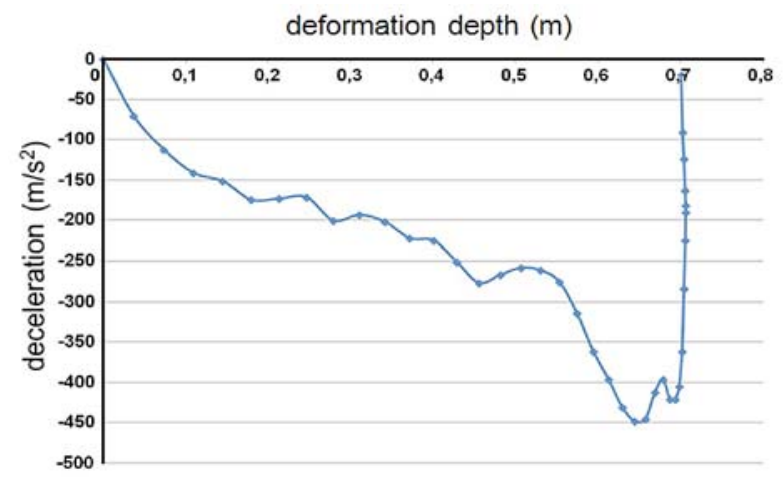

Fig. 11 Deformation depth - Deceleration diagram $($ Renault Laguna $-E E S=62 \mathrm{~km} / \mathrm{h})$

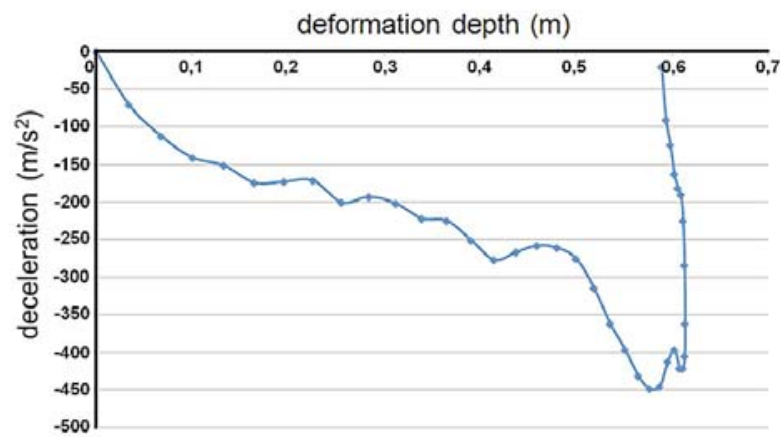

Fig. 12 Deformation depth - Deceleration diagram (Honda Accord - EES $=58 \mathrm{~km} / \mathrm{h})$

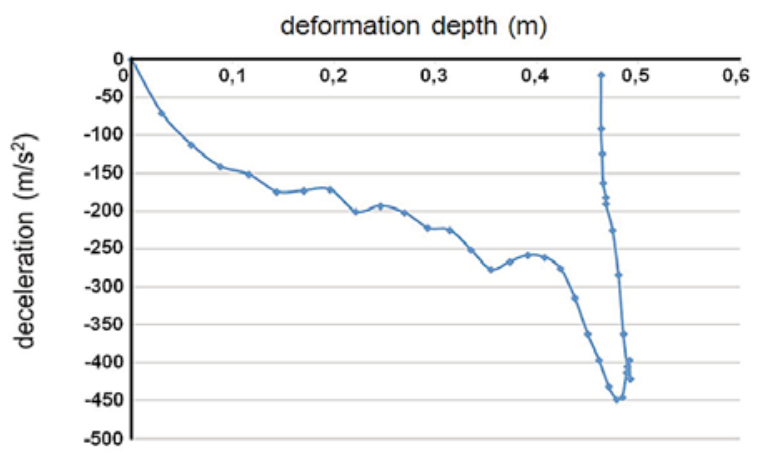

Fig. 13 Deformation depth - Deceleration diagram (Nissan Primera - EES $=54 \mathrm{~km} / \mathrm{h}$ )
In all three diagrams the course of deceleration depending on the deformation depth can be divided into three approximately linear areas with characteristic points A and B (see Fig. 14).

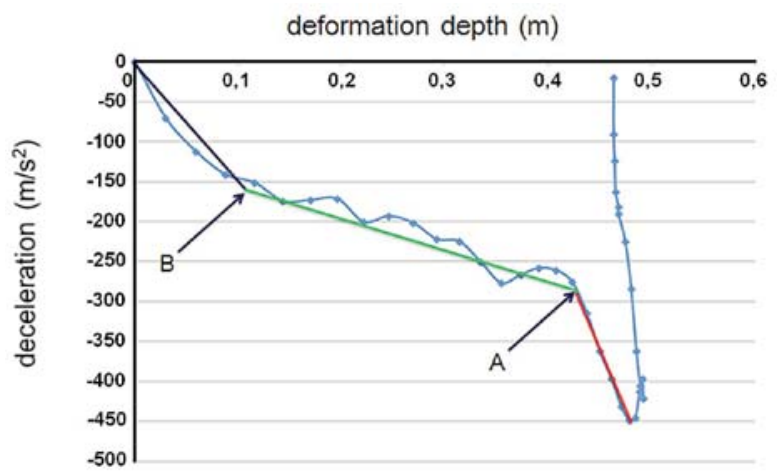

Fig. 14 Deformation depth - Deceleration diagram $($ Nissan Primera $-E E S=54 \mathrm{~km} / \mathrm{h})$

From a comparison of the diagrams follows:

1. The position of point B (approximately $0.1 \mathrm{~m}$ and $150 \mathrm{~m} / \mathrm{s}^{2}$ ) is almost identical for all three vehicles (Nissan Primera, Honda Accord and Renault Laguna).

2. The position of point $\mathrm{B}$ in terms of achieved deceleration (approximately $300 \mathrm{~m} / \mathrm{s}^{2}$ ) is almost identical.

3. The position of point $B$ in terms of deformation depth is similar for the vehicles Honda Accord and Renault Laguna (about 0.53 meters), and different in comparison to the vehicle Nissan for about $0.43 \mathrm{~m}$.

For comparison of the presented diagrams with an older generation of vehicles an analogous procedure with 4 crash tests of a Ford Escort vehicle was performed. It was executed by the company DSD LINZ (Austria) in 1996 [1]. The given courses and impact velocity for a given crash test are shown in Fig. 15.

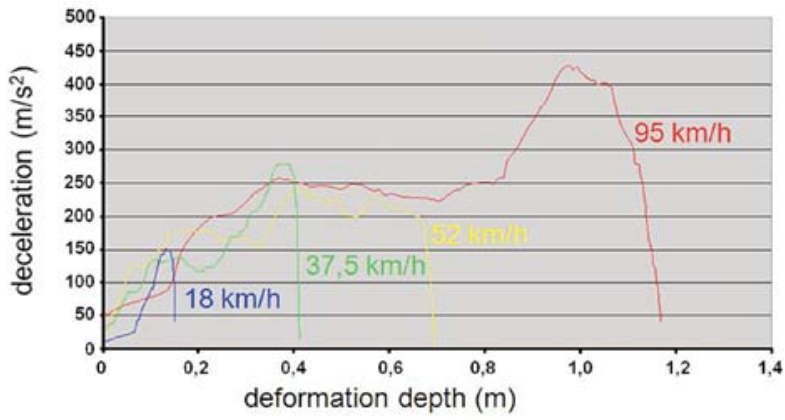

Fig. 15 Deformation depth - Deceleration diagram (Ford Escort - DSD LINZ 1996)

From the comparison of deceleration courses depending on the deformation depth for the vehicles Ford Escort (year of man- 
ufacture about 1986) versus crash tests performed by the Institute of Forensic Engineering, University of Zilina (see Fig. 16) it can be stated that for the vehicles produced around 2000, there is almost a linear increase between the points marked as A and B. Consequently, from point $B$ there is a significant increase of deceleration which means a significant increase of stiffness at the deformation depth of $0.5 \mathrm{~m}$.

For the vehicles Ford Escort an area could be identified where the deceleration was almost constant within a relatively large range of the deformation depth. Such effect was not detected for the vehicles tested by the Institute of Forensic Engineering, University of Zilina. A significant increase of deceleration (and hence stiffness) for the vehicles Ford Escort occurs only at the deformation depth of about $0.85 \mathrm{~m}$.
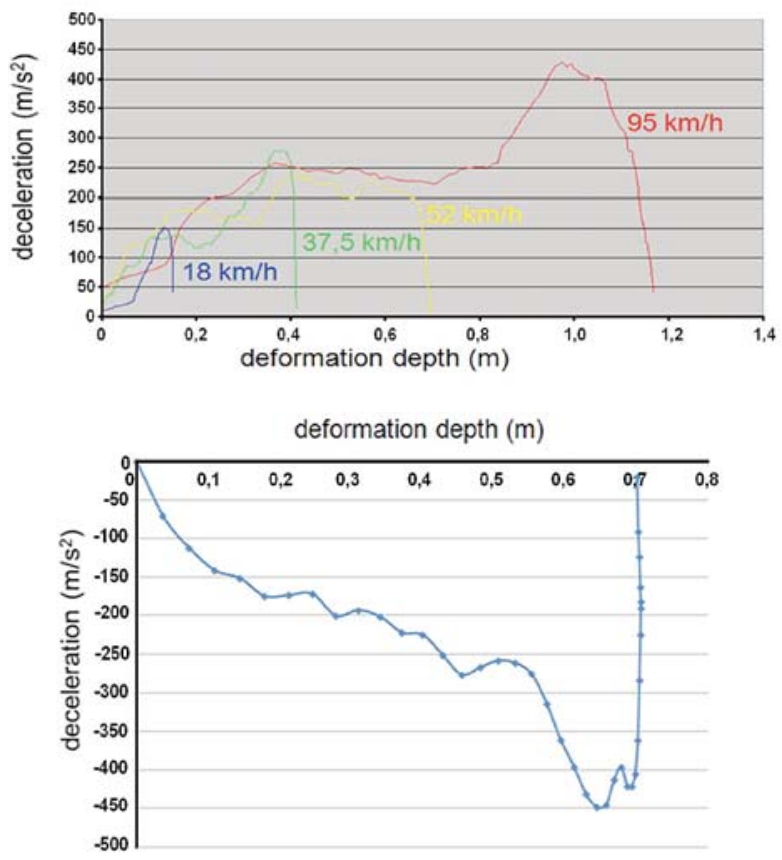

Fig. 16 Comparison Deformation depth - Deceleration diagrams of cars Ford Escort (Crash tests DSD LINZ 1996) and

Renault Laguna (Crash tests Institute of Forensic Engineering, University of Zilina 2012)

\section{Conclusion}

From the tests performed it is concluded that for the newer generation of vehicles - production year around 2000 it will be more
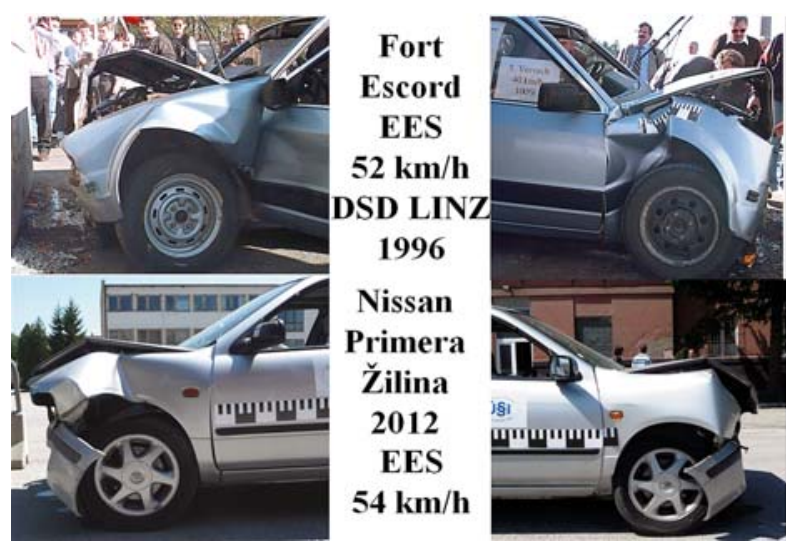

Fig. 17 Comparison damage of cars Ford Escort (Crash tests DSD LINZ 1996) and test car Nissan Primera (Crash tests Institute of Forensic Engineering, University of Zilina 2012) [2]

difficult to properly identify the EES of the given vehicle (under conditions where EES exceeds $50 \mathrm{~km} / \mathrm{h}$ ) versus the older generation of vehicles (which were subject of tests - Crash tests DSD LINZ 1996). This is due to the significantly different course of deceleration and, therefore, also due to the course of stiffness of vehicles, at crash velocities above $50 \mathrm{~km} / \mathrm{h}$. Such difference is evident also from the comparison of the extent of damage, as shown in Fig. 17.

The significant difference between the vehicles Ford Escort and vehicles tested by the Institute of Forensic Engineering, University of Zilina is reflected also in terms of dependency of a shorter wheelbase and impact velocity (see Fig. 18).

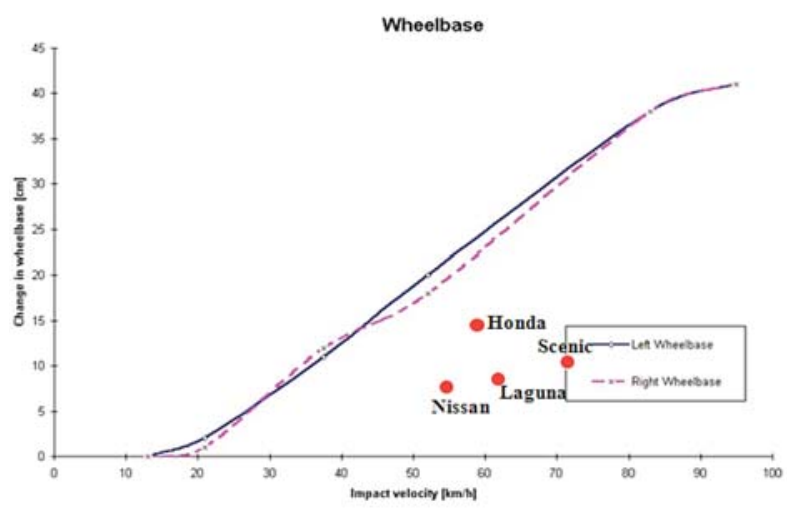

Fig. 18 - Comparison Change in wheelbase for cars Ford Escort (Crash tests DSD LINZ 1996) and for test cars Honda Accord, Nissan Primera, Renault Laguna and Renault Megane Scenic (Crash tests Institute of Forensic Engineering, University of Zilina) [2]

\section{References}

[1] KOHUT, P.: Energeticky ekvivalentna rychlost a prerozdelenie EES - cast 2, Znalectvo vol. 9, No. 3-4, 2004, ISSN 1335-1133.

[2] CD DSD LINZ, 1996. 